\title{
Advantages and Disadvantages of Various Dry-off Methods for Dairy Cows ${ }^{1}$
}

\author{
Pornpamol Pattamanont, Marcos Marcondes, and Albert De Vries ${ }^{2}$
}

\section{Introduction}

The dry period is the period from the end of a lactation to the beginning of a new lactation. During this period, no milk is produced. The typical dry period lasts 40 to 70 days before the next calving when lactation starts again. Dry-off day refers to the day that the dairy farmer decides to stop milking the cow and start the dry period. The purpose of the dry period is 1) to allow rebuilding of the mammary gland, 2) to treat any existing mammary infections, and 3) to prevent new infections.

In the United States, two dry-off protocols are distinguished. One protocol is based on a time schedule based on the expected calving date ( $89.8 \%$ of cows, $98.8 \%$ of farms) (Table 1). Dry-off based on a time schedule is commonly done 40 to 60 days before the expected calving date. The other protocol is based on the cow reaching a minimum milk production level, which is usually 15 to $18 \mathrm{~kg}$ (33 to 40 pounds) (10.2\% of cows, $81.3 \%$ of farms) (Table 1$)$.

After deciding the dry-off protocol, the method used to dry off cows could be either abrupt or one of three gradual ways. Abrupt dry-off is to suddenly stop milking, while gradual dry-off methods aim to reduce milk yield before the dry-off date. The main reason for using gradual dry-off is because lower milk yield at dry-off is often associated with a lower risk of mastitis in the subsequent lactation. Gradual dry-off is achieved through gradual milking, gradual feeding, or administration of a prolactin inhibitor. The USDA (2016) reported that $82 \%$ and $18 \%$ of cows in the US were abruptly and gradually dried-off, respectively. This document reviews advantages, disadvantages, and cost of these four dry-off methods and gives recommendations for practical dry-off management.

\section{General Dry-off Procedure}

At dry-off, involution (the state of the mammary gland that changes from lactating to non-lactating) is initiated by a sudden cessation of milk removal. After dry-off, the udder is susceptible to new infections from contagious and environmental pathogens once milk accumulates in the udder for the next 7 days. This occurs because the teat canal is shortened from udder pressure and the keratin plug has not completely formed. A dry-off procedure includes a dry-off method, dry cow treatment, and management throughout the dry period. The dry-off procedure starts from 14 days before the planned last milking until calving.

The dry-off method, an approach to stop or prepare to stop milking cows at dry-off, is mainly responsible for reducing the risk of new intramammary infections. Dry-off treatment supports the reduction of new infections and treats existing ones. Dry cow management throughout the dry period, which includes feeding appropriate dry cow rations, grouping cows by dry period length or body condition score, and sanitizing and maintaining a good environment

1. This document is AN360, one of a series of the Department of Animal Sciences, UF/IFAS Extension. Original publication date June 2020. Visit the EDIS website at https://edis.ifas.ufl.edu for the currently supported version of this publication.

2. Pornpamol Pattamanont, Ph.D. student, Department of Animal Sciences; Marcos Marcondes, professor, Department of Animal Science, Federal University of Vicosa, Brazil; and Albert De Vries, professor, Department of Animal Sciences; UF/IFAS Extension, Gainesville, FL 32611.

The Institute of Food and Agricultural Sciences (IFAS) is an Equal Opportunity Institution authorized to provide research, educational information and other services

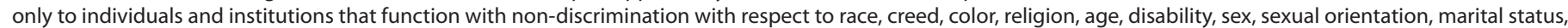

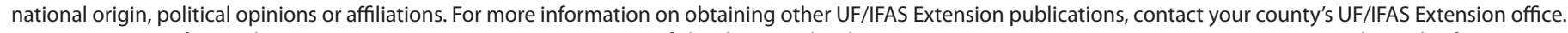
U.S. Department of Agriculture, UF/IFAS Extension Service, University of Florida, IFAS, Florida A \& M University Cooperative Extension Program, and Boards of County Commissioners Cooperating. Nick T. Place, dean for UF/IFAS Extension. 
in dry cow facilities, is also important to sustain cows' health and prevent new intramammary infections, especially the last 2 to 3 weeks before calving.

Dry cow therapy is infusion of antibiotics and/or teat sealants into udder quarters of the cow at the dry-off day with the aim of preventing and treating infections during the dry period. With antibiotics, existing infections as well as new infections during the beginning of the dry period are reduced. Dry cow therapy is divided into "blanket" and "selective" therapies. Blanket dry cow therapy, which is used for the majority of treatments ( $93 \%$ of cows) in the US (USDA 2016), implies that antibiotics are infused in all quarters of all cows in the herd, independent of intramammary infection status. However, applying blanket dry cow therapy to cows that do not need antibiotics can cause antimicrobial resistance in mastitis-causing organisms.

Selective dry cow therapy means that no antibiotics are given to some cows or teats at dry-off. Candidates for selective dry cow therapy are cows with low somatic cell counts during the 3 months before dry-off. Herds with a low incidence of subclinical mastitis are well suited for selective dry cow therapy.

Cows are often given internal teat sealants after dry cow therapy. Internal teat sealants are infusions of a paste into each teat that create a physical barrier for organisms. Teat sealants reduce new infections for a few days after dry-off when the keratin plug, a natural barrier that is made of a waxy substance located at the teat end, has not completely formed.

\section{Abrupt Dry-off}

Abrupt dry-off is the most common dry-off method which is applied by $73.6 \%$ of dairy farms in the US. In this method, milking is suddenly terminated on a day based on a schedule, which is normally determined by the expected calving date and a desired dry period length. Abrupt dry-off is usually recommended for cows with milk yield lower than 15 to $18 \mathrm{~kg}$ ( 33 to 40 pounds) at the dry-off date or for cows that produce less than another farm-set target at dry-off.

Advantages of abrupt dry-off are convenience and less labor than other dry-off methods. Moreover, there is no reduced milk production before the dry-off date compared with the gradual methods. Thus, revenue from milk yield before dry-off is higher for cows that are abruptly dried off.
The disadvantage of abrupt dry-off is an increased risk of mastitis due to the greater risk of leaking milk and intramammary pressure at dry-off, which is most likely to happen with high-producing cows. For example, the odds of getting mastitis increase by $77 \%$ for every $5-\mathrm{kg}$ (11-pound) increase in milk yield above $12.5 \mathrm{~kg}$ (28 pounds) at dryoff. Although udder pressure increases in all cows after dry-off, udder pressure is the highest in high-producing cows and the lowest in low-producing cows. This leads to udder engorgement (swelling) and might lead to mastitis. Furthermore, to abruptly dry off cows with milk yield above 25 to $30 \mathrm{~kg} /$ day (55 to 66 pounds/day) may result in less lying time during the 3 days after dry-off. Less lying time increases acidosis and lameness from lower rates of rumination and saliva production. Blanket dry cow therapy is usually recommended to reduce risk of intramammary infection for cows abruptly dried off, especially when milk yield at dry-off is high.

\section{Gradual Milking}

Gradual milking is the approach to reduce milk yield before dry-off by reducing milking frequency, when pregnant cows are normally milked 2 or 3 times per day. This results in a decline of milk secretion and stimulates mammary gland involution. A few studies investigated the effect of milking frequency before dry-off on udder health.

Workers in New Zealand evaluated milking cows once or twice per day during their last 7 days of lactation. In their study, extra labor was needed to sort these cows before milking into a separate barn. They showed that milk yield at dry-off was reduced by $21 \%$, from $8.9 \mathrm{~kg}$ down to $7.0 \mathrm{~kg}(20$ pounds down to 15 pounds), in cows milked once per day compared to cows milked twice per day.

In a study conducted in the US, some cows in 6 herds were assigned to abrupt dry-off and others were assigned to gradual milking. The cows were sorted either by using a holding pen in the milking parlor or using leg bands. Milking frequency was reduced from 2 times to 1 time (96 cows) and 3 times to 1 time (101 cows). Milk yield at dry-off was not significantly different between both dry-off methods (22.2 $\mathrm{kg}$ (49 pounds) from 197 cows with gradual milking and $21.8 \mathrm{~kg}$ (48 pounds) from 231 cows with abrupt dry-off). No difference in mastitis incidence between gradual milking from 2 times to 1 time and from 3 times to 1 time was observed.

The advantage of gradual milking over abrupt dry-off is a reduced risk of new intramammary infections both in the dry period and after calving as a result of reduced milk 
yield at dry-off, reduced risk of milk leaking, and lower intramammary pressure. In one study, gradual milking reduced the mastitis rate in the subsequent lactation of primiparous cows by 3.5 times but did not show a reduction of mastitis rate in multiparous cows. This could be a consequence of greater persistency in primiparous cows that results in higher milk yield at dry-off. In addition to benefits to udder health, gradual milking increased test-day milk yield in the first 120 days by $1.62 \mathrm{~kg} /$ day (3.56 pounds/ day).

Although many studies supported gradual milking in order to reduce milk yield before dry-off, one study claimed that this method had the disadvantage of slowing down the generation of keratin in the teat end. Therefore, cows that are gradually milked should be milked at least once per day to reduce the risk of mastitis. Another disadvantage of gradual milking is the negative effect of udder enlargement and inflammatory response on cow comfort compared to the gradual feeding method discussed below. In addition, cows with a reduced milking frequency spend less time lying down, which is a sign of cow discomfort.

\section{Gradual Feeding}

Gradual feeding is the approach to reduce milk yield by slowing down the rate of glucose transportation to the mammary gland through feeding. Gradual feeding can be done by several ways, such as taking away concentrates during 14 days before dry-off, reducing dry matter intake for 14 days, giving a lower-energy diet 7 days before dry-off, or taking away hay for 5 days before dry-off.

There are a few studies explaining in detail how to gradually feed cows in the US and in other countries. One study investigated the effects of two different feeding strategies: ad libitum straw and ad libitum straw plus $4 \mathrm{~kg}$ (8.8 pounds) of dry matter silage per day before dry-off. The cows were fed these diets for 5 days before dry-off and were milked twice a day until day 6, which was the first day of the dry period. Cows were milked only in the morning for days 3 and 5 of the dry period. Daily milk yield for the straw cows dropped from $16.8 \mathrm{~kg}$ down to $9 \mathrm{~kg}$ ( 37 pounds/day down to 20 pounds/day) throughout the 5 testing days and was $2.3 \mathrm{~kg}$ (4.8 pounds) on days 3 and 5 of the dry period. Daily milk yield for the straw and silage group fell from $17.3 \mathrm{~kg}$ down to $9.2 \mathrm{~kg}$ ( 38 pounds down to 20 pounds) throughout the 5 testing days before dry-off and was $4.2 \mathrm{~kg}$ (9.2 pounds) on days 3 and 5 of the dry period. Additionally, feeding only straw may have contributed to more negative effects on cow health, such as decreased heart rate at dry-off, increased plasma cortisol concentration, and increased somatic cell counts. Therefore, the gradual feeding method was effective to reduce milk yield prior to dry-off. However, the extent of the feed restriction during the gradual feeding period should avoid excessive metabolic stresses. This was achieved, in this study, by adding $4 \mathrm{~kg}$ (9 pounds) of dry matter silage to the straw diet.

A study from New Zealand explained procedures of gradual feeding for cows in a pasture-based system. Cows were provided with fresh pasture and were supplemented with silage only in the morning. Two treatments were used. The control-group cows were fed $16 \mathrm{~kg}$ ( 35 pounds) per day: $8 \mathrm{~kg}$ (17.5 pounds) dry matter from pasture and $8 \mathrm{~kg}$ (17.5 pounds) from pasture silage. The second group was fed only $8 \mathrm{~kg}$ ( 17.5 pounds) per day of dry matter with half of the dry matter coming from pasture for 14 days prior to dry-off. Daily milk yield at dry-off was reduced by $24 \%$, from $9.1 \mathrm{~kg}$ to $6.9 \mathrm{~kg}$ (20 pounds down to 15 pounds), when dry matter intake was reduced by $50 \%$.

The advantage of gradual feeding is reduced milk yield at dry-off, which is associated with reduced risk of new intramammary infection. Gradual feeding might be more beneficial than gradual milking for the cow because the lower milk yield is induced by reduction of nutrients to the mammary gland rather than by the mechanism of udder pressure that contributes to udder engorgement. One study found that milk leakage is less than half for cows with reduced dry matter intake compared to cows that were abruptly dried off. Thus, lower risk of mastitis from milk leakage is presumed for gradual feeding compared to gradual milking. A lower risk of mastitis could also increase the use of selective dry cow therapy, which results in decreased cost of dry-off treatment and less use of antibiotics.

Although reducing milk yield by gradual feeding is more effective than by gradual milking, there are disadvantages of this method. Gradual feeding through reducing dry matter intake could elevate stress levels of cows. This stress may lead to impaired immunity and a negative energy balance. In addition, a negative effect on calf birth weight is a concern if severe nutritional deficiency or low nutrition occurs longer than 80 to 90 days during gestation. However, those studies were conducted with longer periods of feed restriction, and the effect of 7 to 14 days of feed restriction on pregnant cows' metabolism and its effects on offspring are not clear. Thus, the better way to reduce milk yield before drying off might be feeding cows a lower-energy diet instead of restricting dry matter intake. Another disadvantage of gradual feeding is the additional labor requirement. This means that gradual feeding is less feasible 
on smaller dairy farms where feeding cows with many total mixed rations is problematic. Nevertheless, farms with robotic milking systems could apply gradual feeding more easily because of the ability to adjust the feed ration with the robotic milking machine.

\section{Prolactin Inhibitor Administration}

A prolactin inhibitor is a compound that reduces the synthesis and release of prolactin, one of the hormones responsible for maintaining milk production. Because prolactin has antiapoptotic effects (i.e., the reduction of mammary epithelial cells by shrinkage and budding of the entire cell during involution), inhibition of this hormone promotes mammary gland remodeling. Examples of prolactin inhibitors are quinagolide and cabergoline. Due to the additional cost, dairy farmers might decide to apply a prolactin inhibitor only to cows that have a daily milk yield greater than 15 to $18 \mathrm{~kg}$ (33 to 40 pounds) at dry-off.

The effect of daily injections of $1 \mathrm{mg}$ of quinagolide for 9 weeks prior to dry-off (63 injections) on the inhibition of prolactin release was studied. Quinagolide resulted in $5.3 \mathrm{~kg} /$ day (11.7 pounds/day) lower milk yield during the last 4 weeks compared to yields of control cows (injected with water). Another study reported that injecting $2 \mathrm{mg}$ of quinagolide twice a day for 8 days, 4 days before dry-off, at dry-off, and 3 days after dry-off, reduced the average milk yield 4 days before dry-off by $20 \%$, from $19.3 \mathrm{~kg} /$ day down to $15.5 \mathrm{~kg} /$ day (42 pounds/day down to 34 pounds/day).

Cabergoline is an ergot derivative that affects inhibition of prolactin. In one study, the overall results of cabergoline administration were reductions in prolactin secretion, udder engorgement and milk leakage, and improved lying time. A single injection of cabergoline $(5.6 \mathrm{mg})$ at dry-off reduced prolactin up to 8 days after dry-off and resulted in $28 \%$ milk reduction in goats and a $22 \%$ reduction in dairy cows.

The advantage of a single prolactin inhibitor administration is a combination of a reduced milk yield at dry-off and little extra labor or facilities needed. Several studies supported the use of a prolactin inhibitor because of the convenience for the protocol compliance and the reduction of milk secretion without elevating stress levels from hunger or udder engorgement.

The prolactin inhibitor method may have 2 disadvantages. Cows with higher somatic cell counts but low milk yield before dry-off may not benefit from prolactin inhibitor administration because the incidence of mastitis may not be reduced. Customer perception might be another disadvantage as injection of a derivative compound into cows may be a concern.

\section{Cost of Each Dry-off Method for an Example Dairy Farm}

Estimated cost of the 4 dry-off methods (abrupt dry-off, gradual milking, gradual feeding, and cabergoline injection) are illustrated with a partial budget (Table 2). For this illustration, we simulated a farm with 1,000 total cows with $15 \%$ of cows dried off at any time in a year with a regular dry period length at 60 days. Cows are assumed to produce $25 \mathrm{~kg}$ (55 pounds) of milk yield at dry-off (or at the beginning of the gradual period). Milking frequency is assumed to be twice per day. The dry-off protocol is to dry-off 17.5 cows once per week and treat all cows with blanket dry cow therapy.

In addition to the basic cost of dry-off, the partial budget of costs and revenues for each dry-off method is calculated from all cost differences (labor, feed, mastitis, cabergoline), milk price, and biological data such as reductions in milk yield and risks of mastitis. Throughout the calculations, abrupt dry-off is presented as the reference method. Thus, cost and revenue differences of the gradual dry-off methods are relative to the reference.

We assumed that the numbers of days to apply gradual milking and gradual feeding are 7 and 14, respectively. The prolactin inhibitor is applied just once on the day of dryoff. Labor cost is assumed to be $\$ 12 /$ hour. The difference of labor cost is considered only for gradual feeding and prolactin inhibitor. With 30 seconds per day per cow for 14 days of the gradual feeding period, total variable labor cost is $\$ 1.40$ per cow for gradual feeding. A fixed cost of $\$ 10$ per day for all dry cows is considered only for gradual feeding, in which cost per one cow depends on the number of cows in the gradual feeding program. Fixed cost for gradual milking was not included as it was equal to savings with parlor detergent and labor for milking. In our sample farm, there are 150 dry cows and 2.5 cows are dried per day (calculated as 150 dry cows/60 days dry), or 17.5 dry cows per 7 days or 35 cows per 14 days. With the number of dry cows during 14 days of the gradual feeding period, fixed costs were estimated as $\$ 4.00$ ( $\$ 10$ divided by 35 dry cows $\times$ 14 days).

Total labor cost of prolactin inhibitor administration is $\$ 2.00$ assuming it takes 10 minutes per cow. There is no difference of labor cost for gradual milking because cows are 
allowed to go through the parlor in every milking although they are not being milked.

Feed cost during the gradual period is calculated for all methods with the assumption that feed cost is $\$ 0.21 / \mathrm{kg}$ (\$0.095/pound) dry matter intake. Dry matter intake for all methods, except for gradual feeding, is calculated from an equation based on milk yield, body weight, and days after calving. Dry matter intake of gradual feeding is calculated as $50 \%$ of the dry matter intake of the day of abrupt dry-off. Total feed cost differences from the abrupt method are $-\$ 1.44$ for gradual milking, $-\$ 31.56$ for gradual feeding, and $\$ 0$ for the prolactin inhibitor.

Revenue of milk production during the gradual period and cost of clinical mastitis in the subsequent lactation are related to milk yield during the gradual period and milk yield at dry-off, respectively. Milk yield of cows during gradual milking and gradual feeding are $21 \%$ and $24 \%$ less than at the beginning of the gradual period. Assuming that the milk price is $\$ 0.33 / \mathrm{kg}$ ( $\$ 0.15 /$ pound), total revenue differences from the abrupt method are $-\$ 6.06,-\$ 13.86$, and $\$ 0$.

We assumed that the incidence of mastitis in the subsequent lactation was $45 \%$. The incidence of mastitis is $17 \%$ lower for cows that undergo gradual milking and gradual feeding relative to cows that are abruptly dried off. With prolactin inhibitor, the incidence is $22 \%$ lower compared with cows that are abruptly dried off. We assumed that the cost of clinical mastitis per case is about $\$ 444$. Thus, expected clinical mastitis cost differences with abruptly dried-off cows are $\$ 33.63$ for gradual milking and gradual feeding, and $\$ 24.42$ for prolactin inhibitor.
In these example partial budgets, the most preferable method to minimize the cost of dry-off of the sample herd ( 1,000 cows with $15 \%$ dry cows and $25 \mathrm{~kg}$ ( 55 pounds) of milk yield at dry-off) is gradual feeding ( $\$ 45.94$ more net revenue than abrupt dry-off). The second and third preferable methods are gradual milking ( $\$ 29.01$ more net revenue than abrupt dry-off) and abrupt dry-off.

The partial budget in Table 2 is meant for illustration. Conditions on individual dairy farms may vary and could result in different ranking of the dry-off methods. We recommend that dairy farmers evaluate these 4 dry-off methods for their own farms using the guidelines and example calculations shown in Table 2.

\section{Reference}

USDA. 2016. Dairy 2014, Milk Quality, Milking Procedures, and Mastitis in the United States, 2014. USDA-APHIS-VSCEAH-NAHMS. Fort Collins, CO. \#704.0916.

Table 1. Percentage of operations by dry-off protocol, dry-off method, herd size, and region.

\begin{tabular}{|c|c|c|c|c|c|c|c|c|}
\hline & \multicolumn{4}{|c|}{ Percent Operations } & \multicolumn{4}{|c|}{ Percent Cows } \\
\hline & \multicolumn{3}{|c|}{ Herd Size } & \multirow[t]{2}{*}{ All Operations } & \multicolumn{3}{|c|}{ Herd Size } & \multirow[t]{2}{*}{ All Operations } \\
\hline & Small' & Medium $^{2}$ & Large $^{3}$ & & Small' & Medium $^{2}$ & Large $^{3}$ & \\
\hline \multicolumn{9}{|l|}{$\begin{array}{l}\text { Dry-off } \\
\text { protocols }\end{array}$} \\
\hline $\begin{array}{l}\text { Set schedule of } \\
40-60 \text { days }\end{array}$ & 97.8 & 100 & 100 & 98.8 & 86.7 & 89.7 & 90.2 & 89.8 \\
\hline $\begin{array}{l}\text { Minimum milk } \\
\text { production }\end{array}$ & 74.4 & 85.5 & 94.4 & 81.3 & 13.4 & 10.3 & 9.8 & 10.2 \\
\hline \multicolumn{9}{|l|}{ Dry-off methods } \\
\hline Abrupt & 65.1 & 82.1 & 85.4 & 73.6 & 50.4 & 77.6 & 86.4 & 82.0 \\
\hline Gradual milking & 66.4 & 29.8 & 19.3 & 47.5 & 49.2 & 18.9 & 13.4 & 17.3 \\
\hline Othergradual & 1.8 & 2.3 & 0.6 & 1.7 & 0.4 & 3.5 & 0.2 & 0.7 \\
\hline $\begin{array}{l}\text { Source: Adapted } \\
{ }^{1} 30-99 \text { cows } \\
{ }^{2} 100-499 \text { cows } \\
{ }^{3} \geq 500 \text { cows }\end{array}$ & n USDA & & & & & & & \\
\hline
\end{tabular}


Table 2. Example partial budget of cost and revenue per cow for different dry-off methods for a dry period of 60 days $^{1}$ (pounds inside parentheses).

\begin{tabular}{|c|c|c|c|c|}
\hline \multirow[t]{2}{*}{ Variable } & \multicolumn{4}{|c|}{ Dry-off Methods } \\
\hline & Abrupt & Gradual Milking & Gradual Feeding & Prolactin Inhibitor ${ }^{4}$ \\
\hline Start of the method before subsequent calving (days) & 60 & 67 & 74 & 60 \\
\hline Day(s) to apply & 1 & 7 & 14 & 1 \\
\hline Time to apply (min/day) & - & - & 0.5 & 10 \\
\hline Total time to apply (min) & - & - & 7 & 10 \\
\hline B. Total labor cost difference from Abrupt (\$) & - & - & 1.40 & 2.00 \\
\hline C. Fixed cost $(\$)^{2}$ & - & - & 4.00 & - \\
\hline Average dry matter intake $(\mathrm{kg} / \text { day })^{3}$ & $21.47(47.23)$ & $20.49(45.08)$ & $10.74(23.63)$ & $21.47(47.23)$ \\
\hline Total dry matter intake difference from Abrupt (kg) & - & $-6.84(-15.05)$ & $-150.30(-330.66)$ & - \\
\hline D. Total feed cost difference from Abrupt (\$) & - & -1.44 & -31.56 & - \\
\hline Milk loss (\%) & - & 21 & 24 & - \\
\hline Milk yield at dry-off (kg/day) & $25(55)$ & $19.75(43.45)$ & $19(41.8)$ & $25(55)$ \\
\hline Average milk yield during gradual period (kg/day) & $25(55)$ & $22.38(49.24)$ & $22(48.4)$ & $25(55)$ \\
\hline Total milk loss (kg) & - & $18.83(41.43)$ & $42(92.4)$ & - \\
\hline A. Total revenue difference from Abrupt $(\$)$ & - & -6.06 & -13.86 & - \\
\hline Reduction in incidence of mastitis (\%) & - & 17 & 17 & 22 \\
\hline Incidence of mastitis in subsequent lactation (\%) & 45 & 37 & 36.99 & 39.06 \\
\hline Cost of mastitis ( $\$ /$ cow dried off) & 198 & 164 & 164 & 173 \\
\hline E. Clinical mastitis cost difference from Abrupt (\$) & - & -33.63 & -33.63 & -24.42 \\
\hline F. Prolactin inhibitor injection (\$) & - & - & - & 24.00 \\
\hline Total cost difference from Abrupt: B. + C. + D. + E. + F. & - & -35.07 & -63.51 & 1.58 \\
\hline Total revenue difference (A.)—Total cost difference & - & 29.01 & 49.65 & -1.58 \\
\hline \multicolumn{5}{|c|}{$\begin{array}{l}1 \text { Milk price is } \$ 0.33 / \mathrm{kg}(\$ 0.15 / \text { pound), labor cost is } \$ 12 / \mathrm{hour} \text {, feed cost is } \$ 0.21 / \mathrm{kg} \text { dry matter intake ( } \$ 0.095 / \text { pound), cost of mastitis is } \$ 444 / \\
\text { case. } \\
{ }^{2} \text { Fixed cost per cow is calculated from } \$ 10 \text { divided by } 35 \mathrm{dry} \text { cows. } \\
{ }^{3} \text { Dry matter intake is calculated from } 630 \mathrm{~kg}(1,386 \text { pounds) of body weight, week } 48 \text { of lactation at } 7 \text { days before dry-off, and milk yield at dry- } \\
\text { off. } \\
{ }^{4} \text { Prolactin inhibitor is administered by injecting cabergoline. }\end{array}$} \\
\hline
\end{tabular}

